\title{
Biogeochemical and microbiological characterization of rust tubercles induced by microbial activity
}

\author{
ANNIKA FISKAL ${ }^{1}$, LIPI RAGHUNATHA REDDY ${ }^{2}$, ILONA \\ HERRIG $^{2}$, SVEN-ERIK WULF ${ }^{3}$, JUTTA MEIER $^{4}$ AND \\ HELMUT FISCHER ${ }^{2}$

\section{${ }^{1}$ ETH Zurich} \\ ${ }^{2}$ Federal Institute of Hydrology \\ ${ }^{3}$ Federal Waterways Engineering and Research Institute \\ ${ }^{4}$ University of Koblenz-Landau
}
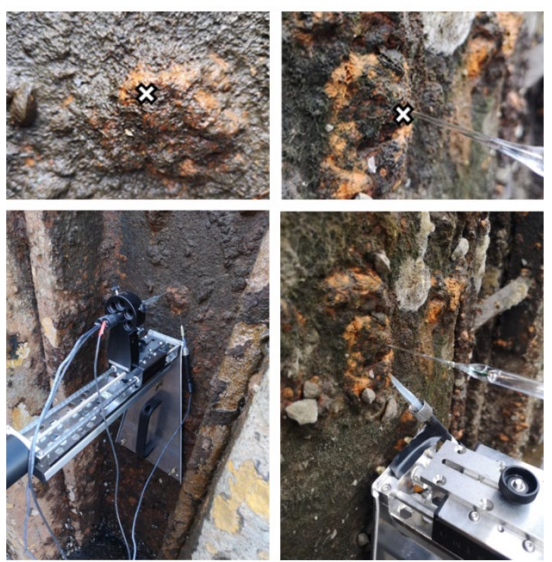

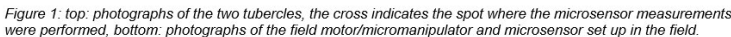

Corrosion of metal structures in the environment can be highly accelerated through microbially induced corrosion (MIC) in biofilms forming at the metal surface [1]. Within the project "RimiK" (risk factors and indicators of microbially induced corrosion), we aim to biogeochemically and microbiologically characterize corrosive biofilms occurring in federal German waterways. Therefore, we applied a field microsensor multimeter coupled to a micromanipulator (Unisense, DK) on corroding sheet piles in a lock (Upper Havel Waterway, Regow, Germany) and investigated rust tubercles formed by MIC. Using a custommade motor and micromanipulator holder we attached the whole set-up to the sheet pile walls using strong neodymium magnets (Figure 1). Thus, we were able to measure profiles into two tubercles directly in the field. We recorded profiles of redox potential $\left(\mathrm{E}_{\mathrm{h}}\right), \mathrm{O}_{2}, \mathrm{H}_{2} \mathrm{~S}$ and $\mathrm{pH}$ with $500 \mu \mathrm{m}$ spatial resolution.

Overall, measured analytes are similar between the two tubercles. However, despite sulfate reducers are thought to play an important role in MIC we detected no free $\mathrm{H}_{2} \mathrm{~S}$. Yet, high $\mathrm{Fe}(\mathrm{II})$ concentrations may precipitate all free $\mathrm{H}_{2} \mathrm{~S}$ produced by sulfate reduction, forming FeS. This was confirmed by a release of $\mathrm{H}_{2} \mathrm{~S}$ after acidification of the tubercle.

$\mathrm{O}_{2}$ concentrations decrease towards the inside of the tubercles, with a maximum penetration depth of $\sim 12 \mathrm{~mm}$. A small increase in $\mathrm{O}_{2}$ concentration close to the surface of one tubercle was observed, likely due to the presence of photosynthetic algae. The $\mathrm{pH}$ decreases towards the center of the tubercle and reaches weakly acidic conditions of $\sim 5.5$, confirming the anodic reaction that takes place there. Redox potential decreases to -350 and -500 $\mathrm{mV}$, indicating a reducing environment.

MIC strongly influenced the chemical micro-environment within the rust tubercles, leading to a micro-environment highly different from the surrounding air/water phase. Using microbial community analysis (NGS) and electron microscopy we will further investigate the spatial organization of the microbial community within the tubercles.

References

[1] Kip, N., \& van Veen, J. A. (2014). The dual role of microbes in corrosion. The ISME Journal, 9(3), 542-551. https://doi.org/10.1038/ismej.2014.169 